\title{
Virtual Engagement: A Nexus Between Internationalisation and Decolonisation of the Curriculum in the PEESA III Project?
}

\author{
Lesley Anne COOKE \\ Durban University of Technology, Durban, South Africa \\ cookela@dut.ac.za \\ Bwalya LUNGU \\ Durban University of Technology, Durban, South Africa \\ Bwalyadutmail@gmail.com \\ Lavern SAMUELS \\ Durban University of Technology, Durban, South Africa \\ samuelsl@dut.ac.za
}

\begin{abstract}
Internationalisation and decolonisation are both prominent issues currently being discussed in South African Higher Education institutions. There is a strong impetus for decolonisation of curriculum design, development and delivery. Experience with the implementation of Collaborative Online International Learning at Durban University of Technology (DUT) has demonstrated that this approach to has immense potential for transformation of learning and teaching. The broader concepts of e-internationalisation and Virtual Engagement allow for even greater flexibility in fostering international collaboration, and opportunities for decolonisation of the curriculum. This paper briefly discusses internationalisation and decolonisation in general and at DUT specifically, and explores the opportunities that VE offers to address these imperatives in the implementation of the Personalised Engineering Education (PEESA) III Project.
\end{abstract}

\section{Keywords: internationalisation, decolonisation, Virtual Engagement, PEESA III.}

\section{INTRODUCTION}

Internationalisation and decolonisation are both prominent issues currently being discussed in South African Higher Education institutions. One focal area in the debates is the transformation of curriculum design, delivery, and learning and teaching methodologies. This is occurring against a backdrop that includes the increasing integration of technology into higher education with a proliferation of online, blended and flexible approaches to learning.

Since 2015 the Durban University of Technology (DUT) has been a pioneer as the first university, in Africa to be extensively involved in an initiative that is led and managed by the State University of New York (SUNY). This initiative is called Collaborative Online International Learning (COIL) which is grounded in an extensive network of partners, and programmes for capacity building academic staff, that have been established by SUNY. COIL promotes the development of a partnership with two academic staff from different geographical regions of the world (drawn from the SUNY partners). The academic partners co-create a short (4-6 week) learning project to be implemented with their respective groups of students. The two academics do not have to be in the same field or discipline, but they agree on clearly defined learning outcomes that jointly align with an area of the curriculum for which they are responsible. When the learning project is implemented 
the students use technology to engage with each other virtually. COIL therefore provides innovative international learning experiences and virtual mobility for both groups of students.

As a result of the four year involvement in COIL at DUT there has been an exponential growth in the interest shown by the academic staff. Thus, the more comprehensive concept of $E$ Internationalisation has recently been adopted which is grounded in the adoption of a broader approach that DUT is calling 'Virtual Engagement' (VE). VE embraces COIL activities with existing SUNY partners, and expands the scope of internationalisation through promoting the establishment of partnerships outside the scope of the SUNY network. This approach also enables DUT to develop and implement its own 'in-house' VE capacity building initiatives for academic staff.

DUT is a partner in the European Union funded Personalised Engineering Education South Africa (PEESA) III Project. The purpose of this paper is to consider the opportunities to interconnect internationalisation and decolonisation of the curriculum for engineering education through the application of VE in the PEESA III Project. The following sections set out brief discussions of: the concepts of internationalisation and decolonisation respectively; the manner in which they are understood at DUT specifically; COIL, e-internationalisation and VE at DUT; and the implications for the PEESA III Project of the use of VE as a nexus between internationalisation and decolonisation.

\section{INTERNATIONALISATION OF HIGHER EDUCATION}

Internationalisation has emerged as one of the defining issues of higher education globally. There is a vast body of literature and engagement in conceptual debates, often without reaching agreement on the meaning of internationalisation (Zeleza, 2012). There is no doubt that over the past 25 years internationalisation has evolved from a marginal and minor element to a global, strategic, and mainstream factor in higher education. It has become a very broad and varied concept and now includes many new rationales, approaches and strategies in different and constantly changing contexts (Knight and De Wit, 2018).

Concomitantly the terminology used to describe international practices has also evolved; internationalisation is a term which has different meanings to individuals and varied interpretations in individual higher education institutions. In 2004 Jane Knight cited her own definition of internationalsiation as being "the process of integrating an international, intercultural or global dimension into the purpose, functions or delivery of post-secondary education" (Knight 2003 cited in Knight 2004).

Notably, more recently Stein (2017) cites Knight (2014) as suggesting that internationalsiation is losing its way and requires a reframing of the guiding principles and values. Over time the focus of internationalisation has shifted from scholarships for foreign students to developments such as branding, international programmes, provider mobility, global citizenship, internationalisation at home, MOOC's, franchising, and joint degrees. Internationalisation has come of age and is addressed in, for example, university strategic plans, national policy statements, international declarations and academic publications. In this shift in focus, there has been a tendency for a transformation from values such as mutual cooperation, partnership exchange and mutual benefits to approaches that are grounded in competition, commercialization, self-interest and status building (Knight and De Wit, 2018). 


\section{INTERNATIONALISATION AT DUT}

Durban University of Technology (DUT) strongly supports internationalisation as an essential element in the delivery of quality higher education. Internationalisation is firmly embedded in the current university strategic plan and goals $(2015$ - 2019) and will become more deeply entrenched in the DUT Strategic Plan 2020 - 2030 which is currently a work-in-progress. In support of the internationalisation initiative, over 10 years ago, DUT established the International Education and Partnerships Directorate. DUT adopts a very broad set of principles around internationalisation that resonate with the broad concept of internationaliation described by Knight and De Wit (2018) above, these DUT principles include:

- Excellence and mutual benefit - establishing partnerships that foster mutual benefit and that promote excellence as a benchmark of internationalisation;

- Equity and institutional culture - internationalisation activities will promote the University's equity and transformation objectives and will contribute to an institutional culture which values diversity;

- Positioning in Africa - increasing linkages and engagement within the SADC region and other African countries;

- Research and academic autonomy - encouraging academic staff to develop international links and collaborations;

- Curriculum - that is relevant to local, regional and international contexts;

- International students - actively promoting registration of international students.

Grounded in the above principles the IEP Directorate activities that support the DUT community in internationalisation include: partnership development; multilateral collaboration; ambassadorial and consular engagements; staff and student mobility programmes; liaison with international education organisations and consular relations; promoting internationalisation of the curriculum; and promoting e-internationalisation.

\section{DECOLONISATION OF HIGHER EDUCATION IN SOUTH AFRICA}

Before exploring the concept of decolonisation it is useful to briefly explore colonisation. Le Grange (2018) explains that first generation colonialism was the conquering of the physical spaces and bodies of the colonized. Second generation colonialism was the colonization of peoples' minds through disciplines such as education, science, economics and law. Neo-colonialism relates to the achievement of technical independence of a country that is still under the influence of the excolonial or newly developed superpowers. Put simply decolonisation is the "undoing of colonization" (Le Grange, 2018: 8).

Decolonisation is not a new discourse in higher education, but now and again events bring about a new-found energy into the conversations. In the case of South African universities, it was during the 2015/16 \#Feesmustfall and \#Rhodesmustfall movements that the decolonisation debates were oiled and 'wheels got spinning'. The calls for decolonisation during these movements were often characterized by violence as student protesters questioned the Eurocentric nature of the curriculum (Fomunyam \& Teferra, 2017; Du Preez, 2018; Le Grange, 2018). As a result the need for higher education institutions to foster and engage in debate around transformation and decolonisation of the curriculum has been reignited.

Furthermore, in the debates there has been a re-emergence of the complex and varied concepts and definitions of decolonisation. It is well recognized that decolonisation is a broad term that different meanings for different people (Mheta, Lungu \& Govender, 2018). In the context of this paper it is not possible to explore the various definitions in depth; extensive analyses of the concept of decolonisation are offered by, for example, Le Grange 2018; Fomunyam \& Teferra, 2017; Du Preez, 2018; Mheta, Lungu \& Govender, 2018). However, it is generally understood that 
decolonisation is about making efforts to challenge the process of colonisation and racialisation, and the historical and continued effects it has on maintaining colonial knowledge (Le Grange 2016; Heleta 2016; Higgs 2016). Furthermore, decolonisation is a process of creating and keeping alive ways of knowing, being and relating that eradicate the strong hold that the process of colonialty created (Stein and Andreotti, 2017).

\section{DECOLONISATION AT DUT}

DUT was not exempt from the decolonisation debate and initiated its own conversations about the issues at hand, in particular the curriculum at the university. Reaching a common understanding of decolonisation is a particular challenge especially at an institution that is so diverse, and with stakeholders who have roots deeply etched in different conceptualisations of colonization. Consequently, the way in which decolonisation was seen as a whole was very fragmented and quite difficult to grasp at DUT.

In response to the need for action a Decolonisation Task Team was formed 2017, and immediately tasked with developing a Position Paper for DUT. The resulting Position Paper discusses the need to explore for example, how the nature of knowledge can be changed, and about finding ways to make a shift from the strong hold of Eurocentric forms of knowledge to knowledge that is more contextual, relevant, and responsive for students at DUT. The paper also suggests that knowledge in the Global South has always centered on Eurocentric and Western (predominantly American) content, contexts, perception and understanding in the curriculum irrespective of whether the focus was about Africa or about the Global North. The aim of decolonisation at DUT is to disrupt this knowledge and begin to find ways to engage previously marginalized knowledge as well as create new knowledge from the South African contexts and realities (Mheta, Kehdinga, Govender, Hemson, Govender, Lungu \& Manjeya 2018).

This shift in the use of knowledge as power (away from a West and North hegemony) resonates with what Knight and De Wit term knowledge diplomacy. Knowledge diplomacy involves the contribution that education and knowledge creation, sharing and use make to international relations and engagement. It is seen as a reciprocal process with knowledge sharing and mutual benefits through a two-way exchange being essential for all involved (Knight and De Wit, 2018).

The stance around decolonisation at DUT and the concomitant participation in the world of knowledge is consciously driven by both its location on the continent and by the realities of South African and African history. Thus the needs of this context, the resources of this environment, and the ways in which African people have developed knowledge to address those needs, and drawn on the resources, inform the ongoing development of knowledge. Secondly, the DUT participates in knowledge production with others around the world as peers, recognizing that their perspective is likewise influenced by their context and location (Mheta, Lungu \& Govender, 2018).

\section{THE RELATIONSHIP BETWEEN INTERNATIONALISATION AND DECOLONISATION AT DUT}

At the outset the caveat that internationalisation initiatives, especially those pertaining to the curriculum, have the potential to become another form of colonisation must be heeded (Pinar, 2010; Du Preez, 2018; \& Majee \& Rees, 2018). A critique of internationalisation in higher education from the departure point of its colonial history to its conceptualisation in the last decade is presented by Stein (2017). In her analysis she interweaves consideration and critique of colonial influences on internationalisation and sets up a framework to provide a summary of critical approaches in higher education. Three approaches are identified: soft, radical and liminal. For each approach the summary includes a view of colonialism together with the desired changes to be brought about. Part of the rationale for the critique offered by Stein is to promote (re)thinking around the ethics and 
politics of how internationalisation in higher education is studied and practiced. This is particularly pertinent for South Africa given the nature of the current debates in higher education, in particular those around internationalisation and decolonisation.

Whilst many may believe that the constructs of decolonisation and internationalisation are mutually exclusive, it is the view of the authors that decolonisation of the curriculum is in fact a call for greater deepening and broadening of internationalsiation. It can be argued that the approach to internationalisation is dominated by a small number of paradigms and a few countries, and that such dominance has strong congruence with the colonial powers. In contrast, a broad approach to internationalsiation would include paradigms and countries that have previously been excluded, or are at the fringes of academic discourse, and allow them to be brought into the centre of the debate; and thus 'given a place at the table'. It is arguable that these additional voices would contribute significantly to the decolonisation debate such that decolonisation would not be seen as a narrow, parochial issue but as a broader challenge that needs an international response.

Some examples of the way in which international engagement could enhance decolonisation comprise: inclusion of indigenous knowledge; a focus on African knowledge; and bringing to the fore excellence in countries that are often marginalized. Examples of the latter include the Health Care System in Cuba, the Happiness Index in Bhutan, and excellence in various spheres in Eastern Europe that are not as prominent as cited exemplars in Western Europe. There are also Western countries that have not been colonial powers, whose education, social and economic systems are worthy of study, such as Ireland and the Nordic countries. Emerging giants such as India and China, together with some of the other Asian Tigers have deep and rich histories, economic and knowledge systems that could enrich a decolonized curriculum.

A colonialised curriculum is, by its very nature, one that is shackled by a narrow, parochial approach, and the dominance of a few over many. A decolonised curriculum should therefore, attempt to break those shackles and to espouse diversity, plurality, and a deep appreciation of 'other'. Internationalisation provides a potent and energizing opportunity to be part of a decolonised curriculum. It must be acknowledged that internationalisation would not be the only approach to a decolonised curriculum but could play an important role in informing a multi-perspective approach towards an enriched, decolonised curriculum.

Arguably, failure to embody internationalisation in the decolonisation debate would be a missed opportunity that could result in a curriculum that is deficient on a number of levels. The inclusion of internationalisation can be part of a dynamic and evolving process (rather than an event) to achieve the ultimate outcome. Internationalisation, has much to offer towards the challenges of an increasingly complex world. Likewise, a decolonised curriculum can be seen as a dynamic construct that continues to evolve in contributing to the challenges of the modern world; not a world that resides totally in, and is dominated by history. A decolonised and internationalised approach would promote the development of a curriculum that is futuristic, alive, vibrant and inspiring. 


\section{E-INTERNATIONALISATION AT DUT}

As explained in the introduction above DUT has actively participated in the SUNY COIL initiative for the last four years. The SUNY Centre for COIL is one of the leading international organsiations focused on the emerging field of Globally Networked Learning - a teaching and learning methodology which provides innovative, cost effective internationalsiation strategies. COIL programmes foster staff and student interaction with peers abroad through co-taught multicultural online and blended learning environments which emphasise experiential student collaboration. The COIL model advocates creation of co-equal learning environments where academic staff work together to generate a shared curriculum based on well-designed coursework that emphasizes experiential and collaborative student learning (SUNY COIL Website http://coil.suny.edu).

According to Louw and Michau (2018) technology in an online teaching environment has the potential to transform learning, widen participation by students and increase learning opportunities. They caution, however, that the focus in such initiatives should be on the teaching and learning rather than the technology. The need for such a focus on pedagogy is reflected in the approach adopted in capacity building initiatives offered by SUNY which are deeply grounded in innovative pedagogy and practice, hearing student voices, appropriate use of the tools and technologies and assessing the impact of the joint projects (http://coil.suny.edu).

At DUT the implementation of the COIL concept is grounded in the integration of technology into pedagogy to facilitate international experiences for students whilst they are at 'home', through short assignments (optimally 4-6 weeks) which are implemented in collaboration with an international SUNY network partner. The focus at DUT has been on internationalisation, and transformation of the curriculum and not on e-learning (using a Learning Management System - LMS) per se. The technology is used as a platform to enhance the classroom experience and encourage students to become independent learners, thus promoting curriculum development and delivery initiatives. Aligned with the SUNY model a key aspect of COIL at DUT has been on the integration of knowledge from South Africa that is shared freely and uncensored with the academic partner and their students. The expansion of COIL projects to partners from, for example, Mexico, Brazil and India, has made major contributions to this shift in knowledge as power towards knowledge diplomacy. Currently the main focus of COIL activities at DUT have centred on undergraduate programmes.

A critical aspect of COIL is building in reflection at every level for the staff and the students involved. Feedback gathered from students who have been involved in these projects demonstrates strongly that their voices have been heard in equal partnerships with their peers, and that the learning experience has been deeper than the achievement of the pre-determined learning outcomes for the project. Students reported that, for example they: became much more aware of their strengths and weaknesses; overcame their fears of communicating with people from other countries; gained confidence in expressing themselves; took more responsibility for responding to comments timeously; acknowledged the intercultural differences and commonalities; appreciated the innovative teaching strategy and felt the learning opportunity was improved because of the collaboration; and were enriching their Curriculum Vitae

Drawing on the COIL experiences, a VE learning experience is designed by two academics one from DUT and one from a different institution (non-SUNY partner) in a different geographical location. The support and capacity building for staff is provided by DUT. The two academics agree on the learning outcomes for the project and the topics to be discussed collectively by the students. Interestingly the academics do not have to be from the same, or related disciplines. Some of the most innovative projects are multi-disciplinary, involving for example, nurses and engineers working on the design of a hospital, or health professional students and law students collaborating on an ethical issue. Once the project has been designed it is implemented with minimal input from the academic staff, whose role now becomes that of overseeing that the student groups are engaging 
with each other. The principles underpinning VE projects are that they are, by their very nature, crafted with mindful attention to ensure that the two groups of students engage in a way that will enhance their intercultural awareness and will promote them to work in international, intercultural teams. Another vital aspect is that the academic staff are free to agree on a platform for communication that can be selected from the range of social media and apps available. The communication platform does not have to be pre-prescribed by the software available to support elearning at the university. Students are also free to come to an agreement to the platform that they will use to communicate synchronously or asynchronously, outside of the platform chosen by the academic staff. Thus, in the implementation of the VE project there are opportunities for different levels of engagement within the student groups using a variety of technologies that transcends the level of the institutional LMS and enable the students to come together collaboratively.

In a nutshell the power of VE projects is that they are low-cost solutions to the internationalisation of the curriculum. The virtual mobility that the students experience through the implementation of the project allows them to exist in a place that they could otherwise not afford, and thus contributes tremendously to the achievement of internationalisation at home. They are provided with an opportunity to engage with their peers in a different country to exchange knowledge and create new knowledge that is both synergistic and shared.

\section{THE PEESA III PROJECT AT DUT}

DUT is one of the eight partner universities in the European Union Funded PEESA III Project. There are three other partners from South Africa together with two from Germany, and one each from Poland and Romania. The inclusion of Poland and Romania in the project is inspiring. Even within a well-resourced system of European countries, Poland and Romania have remained less involved than their Western European counterparts. The mix of partners in the PEESA III project opens up opportunities for the development of curricula that balances the African perspective as well as those from Western and Eastern Europe. The opportunity for DUT staff to work with staff and students from Germany, Poland and Romania adds a diversity that will contribute to new perspectives and plurality that are essential tenets of a decolonised curriculum

According to the PEESA III Project Proposal (2017) one of the key aims is to design three Master degree qualifications in engineering, based on flexible learning paths (blended, distance, on-line learning), that are mutually recognised by the Project partner universities. The associated activities are: curriculum development; the development of learning and teaching tools including those that embed ICT practices; the development of flexible learning paths with the integration of blended, distance and online modes of learning that enable access to the programme for students in full-time employment; and research into innovative practices including student-driven flexible learning paths. Consequently, each of the partner universities has identified the development of one online module as one of their key outcomes for the project. Other aims of the project include: capacity development for curriculum design and development; enhanced digital teaching; enriched intercultural capability; and promotion of real and virtual mobility for staff and students (PEESA III Project Proposal, 2017). The aims of the Project thus align well with the concept of VE as a driver for innovation in learning and teaching, development of intercultural competence, integration of technology and promoting virtual mobility.

\section{VE AS A NEXUS IN THE CONTEXT OF THE PEESA III PROJECT}

VE has been identified as having the powerful potential to be the nexus between internationalisation and decolonisation in curriculum design, development and delivery. As explained earlier, a VE project affords opportunities for students to exchange their own knowledge, from the context of their own location with peers in another country, and vice versa. This thus achieves one of the key 
principles of decolonisation - that knowledge is shared and that African knowledge and perspectives has equal status with those from other contexts.

A counter-argument to VE could be that the development of blended, online, distance learning material will also promote these attributes. However, it is to be expected that the learning materials for the flexible pathway will be available on a selected LMS. At DUT the LMS (currently Blackboard), is used in online (e-learning) to share content, encourage collaboration amongst a student group, and for assessment of learning. Honest reflection reveals that it has had a very slow uptake, and that many staff use the LMS space merely as a repository for notes. Furthermore, online learning at DUT is confined solely to the university with no other partner institutions involved. VE projects offer a different perspective because there is a partner institution and there is greater freedom and flexibility in the choice and application of technology. The experience of COIL at DUT has demonstrated that academic staff respond innovatively to the opportunities the collaborative approach offers.

It is proposed that the stakeholders in the PEESA III Project be given the space and time to deliberate on the concepts of internationalisation, and decolonisation of the curriculum, and the implications for curriculum design in the PEESA III project. It is strongly recommended that projects that resonate with the VE principles are designed and implemented collaboratively by the partner universities to promote international, intercultural and multidisciplinary competences in the Master's degree students.

\section{CONCLUSIONS}

The discussion presented above has sought to briefly explore the concepts of internationalisation and decolonisation generally, and their interpretations at DUT specifically. Innovative approaches to learning and teaching using COIL and VE methodologies have also been discussed. A key purpose for this exploration of the potential of VE to be the nexus between internationalisation and decolonisation is to stimulate discussion with the stakeholders of the PEESA III Project. It is strongly recommended by DUT that the VE principles of curriculum design and implementation of are implemented in the Project.

\section{REFERENCES}

Du Preez, P. (2018). On Decolonisation and Internationalisation of University Curricula: What can we learn from Rosi Braidotti? Journal of Education, 74, 19 - 31. Retrieved 10 May, 2019, from http://dx.doi.org/10.17159/2520-9868/i74a02

Fomunyam, K. G., \& Teferra, D. (2017). Curriculum responsiveness within the context of decolonisation in South African higher education. Perspectives in Education, 35(2), 196-207. Retrieved 01 June, 2019, from http://dx.doi.org/10.18820/2519593X/pie

Heleta, S. (2016). Decolonisation of higher education: Dismantling epistemic violence and Eurocentrism in South Africa. Transformation in Higher Education, 1(1), 1-8. Retrieved 15 May, 2019, from https://doi.org/10.4102/the.v1i1.9

Higgs, P. (2016). The African renaissance and the transformation of higher education curriculum in South Africa. African Education Review, 13(1), 87-101. Retrieved 15 May, 2919, from http://doi.org/10.1080/18146627.2016.1186370

Knight, J. (2004). Internationalisation Remodeled: Definition, Approaches, and Rationales. Journal of Studies in International Education, 8 (1), 5-31. Retrieved 24 April, 2019, from https://journals.sagepub.com/doi/abs/10.1177/1028315303260832 
Knight, J., \& De Wit, H. (2018). Internationalisation of Higher Education: Past and Future. International Higher Education, 95, 2-4. Retrieved 10 May, 2019, from http://dx.doi.org/10.6017/ihe.2018.95.10715

Le Grange, L. (2016). Decolonising the University curriculum. South African Journal of Higher Education, 30(2), 1-12. Retrieved 10 May, 2019, from: https://doi.org/10.20853/30-2-709

Le Grange, L. (2018). Decolonising, Africanising, indigenizing curriculum studies: Opportunities to (re)imagine the field. Journal of Education, 74, 4-18. Retrieved 17 May, 2019, from http://orchid.org/0000-0002-7096-3609

Louw, W., \& Michau, A. (2018). E-Learning: Effective Strategy, or 'Just Another Brick in the Wall'? African Education Review, 15 (3), 38-48. DOI: 10.1080/18146627.2016.1268062. Retrieved 10 May, 2019, from https://www.tandfonline.com/loi/raer20

Majee, U.S., and Ress, S.B. (2018). Colonial Legacies in Internationalisation of Higher Education: Racial Justice and Geopolitical redress in South Africa and Brazil. Compare: A Journal of Comparative and International Education. Retrieved 15 May, 2019, from https://doi.org/10.1080/03057925.2018.1521264

Mheta, G., Lungu, B., \& Govender, T. (2018). Decolonisation of the curriculum: A case study of the Durban University of Technology in South Africa. South African Journal of Education, 38(4), 1-7. Retrieved 08 March, 2019, from https://doi.org/10.15700/sage.v38n4a1635

Mheta, G., Kehdinga, G.F., Govender, V., Hemson, C., Govender, T., Lungu, B., Manjeya, N.C. (2017). Decolonising Higher Education in South Africa: A Durban University of Technology Introspection. A Position Paper. Durban University of Technology.

PEESA III. (2017). Personalised Engineering Education in Southern Africa/PEESA III. Detailed Description of the Project. Call for Proposals 2017 -EAC/A03/2016. Erasmus +. 1 - 104.

Pinar, W.F. (2010). Introduction. In W.F. Pinar (Ed). Curriculum Studies in South Africa: Intellectual histories and present circumstances. New York, Palgrave MacMillan

Stein, S. (2017). Internationalisation for an Uncertain Future: Tensions, Paradoxes, and Possibilities. A Review of Higher Education, 41(1), 3-32. Retrieved 10 May, 2019, from https://doi.org/10.1353/rhe.2017.0031

Stein, S., \& Andreotti, V. (2017). Decolonization and higher education. In M Peters (Ed). Encyclopedia of educational philosophy and theory. Singapore, Springer

SUNY Website. State University of New York. SUNY COIL Center, COIL Activities, Homepage. http://coil.suny.edu

Zeleza, P. T. (2012). Internationalisation in Higher Education: Opportunities and Challenges for the Knowledge Project in the Global South. Keynote Address, Vice-Chancellors Leadership Dialogue Internationalisation in Higher Education: Opportunities and Challenges for the Knowledge Project in the Global South. SARU Leadership Dialogue on Building the Capacity of Higher Education to Enhance Regional Development, Maputo, Mozambique, March 21-22, 2012. Retrieved 01 June, 2019, from http://erepo.usiu.ac.ke/11732/1161 